\title{
The potential of seismic cross-hole tomography for geotechnical site investigation
}

\author{
Yannick Choy Hing $\mathrm{Ng}^{1}$, William Danovan ${ }^{2}$, and Taeseo $\mathrm{Ku}^{1, *}$ \\ ${ }^{1}$ Department of Civil \& Environmental Engineering, National University of Singapore, Singapore \\ ${ }^{2}$ Rail Group, Land Transport Authority, Singapore
}

\begin{abstract}
Seismic cross-hole tomography has been commonly used in oil and gas exploration and the mining industry for the detection of precious resources. For near-surface geotechnical site investigation, this geophysical method is relatively new and can be used to supplement traditional methods such as the standard penetration test, coring and sampling, thus improving the effectiveness of site characterization. This paper presents a case study which was carried out on a reclaimed land in the Eastern region of Singapore. A seismic cross-hole test was performed by generating both compressional waves and shear waves into the ground. The signals were interpreted by using first-arrival travel time wave tomography and the arrival times were subsequently inverted using Simultaneous Iterative Reconstruction Technique (SIRT). A comparison with the borehole logging data indicated that $\mathrm{P}$-wave velocity model cannot provide sufficient information about the soil layers, especially when the ground water table is near the surface. The S-wave velocity model seemed to agree quite well with the variation in the SPT- $N$ value and could identify to a certain extent the interface between the different soil layers. Finally, P-wave and S-wave velocities are used to compute the Poisson's ratio distribution which gave a good indication of the degree of saturation of the soil.
\end{abstract}

\section{Introduction}

The geophysical technique of seismic cross-hole tomography has been around for more than three decades and is well-established in oil and gas exploration (e.g. [19]) and the mining industry (e.g. [10-17]). These include the detection of fractures in rocks, monitoring the changing conditions of reservoirs, delineating mineralisation, among others. Other common applications include the monitoring of carbon dioxide injection and sequestration in the ground (e.g. [18-19]), characterisation of unconfined aquifers (e.g. [20]) and detection of natural cavities (e.g. [21-23]). The application of seismic crosshole tomography for geotechnical site investigation (e.g. [24-25]) is advantageous as it can be used to supplement traditional methods for effective site characterisation. The common practice in Singapore is to drill boreholes, perform the standard penetration test and collect soil samples for laboratory testing at a fixed depth interval, before finally back-filling the borehole. It would be economical if the boreholes could be also used for crosshole seismic measurements, so as to acquire additional information about the soil mass in-between the boreholes.

Most of the reported literature about cross-hole seismic tomography have used $\mathrm{P}$-waves and the depth of investigation ranged from 50 metres to a few hundred metres below the ground surface. On the contrary, the geotechnical engineer is more interested in the nearsurface soil properties such as the shear modulus at smallstrain, which is related to the velocity of the shear waves.
For geotechnical site investigation, while Angioni et al. [24] has used a borehole spacing of $4.80 \mathrm{~m}$, Mackens et al. [25] adopted a spacing of $4 \mathrm{~m}$. Both studies conform to the range recommended by the ASTM standard [26]. However, such short borehole distances are not economical if the site covers a large area.

In this study, both $\mathrm{P}$-wave and $\mathrm{S}$-wave cross-hole seismic tomography was carried out on a reclaimed land in the Eastern region of Singapore, with a borehole-toborehole spacing of $25 \mathrm{~m}$. After inversion of the travel time data, the resulting velocity tomograms are then compared with the available borelog data.

\section{Background of test site}

The test site is located on a reclaimed land which is part of a large reclamation project in Singapore, called the Changi East Reclamation Project. The reclamation project started in 1991 and involved the creation of about $20 \mathrm{~km}^{2}$ of land (delineated in Figure 1) so as to cater for the extension of the Changi International Airport and other infrastructure developments [27]. Prior to the reclamation works, an extensive site investigation program was carried out and it was found that the reclaimed area is underlain by layers of soft marine clay, interspersed by layers of -medium-dense to dense clayey sands of the Singapore Old Alluvium. The thickness of the marine clay layer was found to range from a few metres to over $20 \mathrm{~m}$ partly due to the undulating nature of the underlying Old

\footnotetext{
* Corresponding author: ceekt@nus.edu.sg
} 
Alluvium and the non-uniform consolidation of the marine clay [28]. While the soft and compressible clay layer was improved by a combination of pre-fabricated vertical drains installation and fill surcharge, the densification of the sand layer was conducted by dynamic compaction, Müller resonance compaction and vibroflotation. The reader is referred to the works of Bo et al. [26] for more details about the reclamation project.

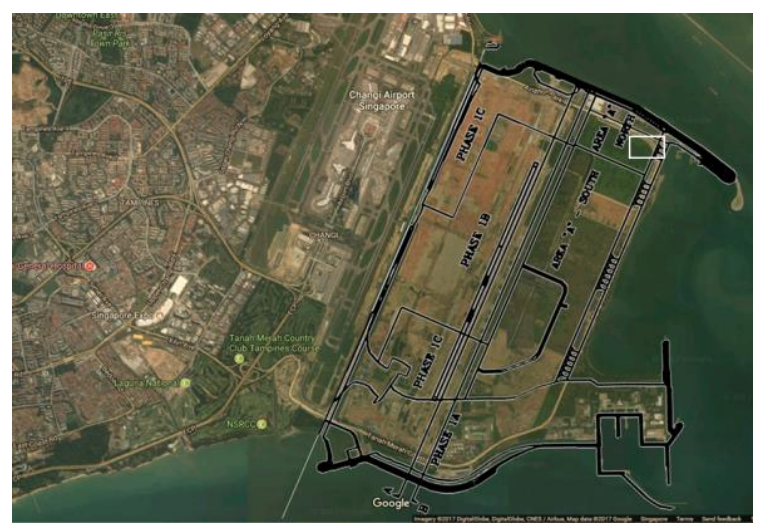

Fig. 1. Satellite view of the reclaimed site as obtained from Google Maps (2017). The white rectangle in area A (North) shows the location of the test site.

The site for seismic cross-hole tomography belongs to the construction phase Area A (North) which started in 1999 and was completed in March 2004. Three boreholes namely $\mathrm{RC} / 1, \mathrm{RC} / 2$ and $\mathrm{RC} / 3$ were drilled in a straight line at a centre-to-centre spacing of $25 \mathrm{~m}$. Standard penetration test SPT- $N$ values were measured at an interval of $\sim 2.5 \mathrm{~m}$. The soil profile is shown in Figure 2 .

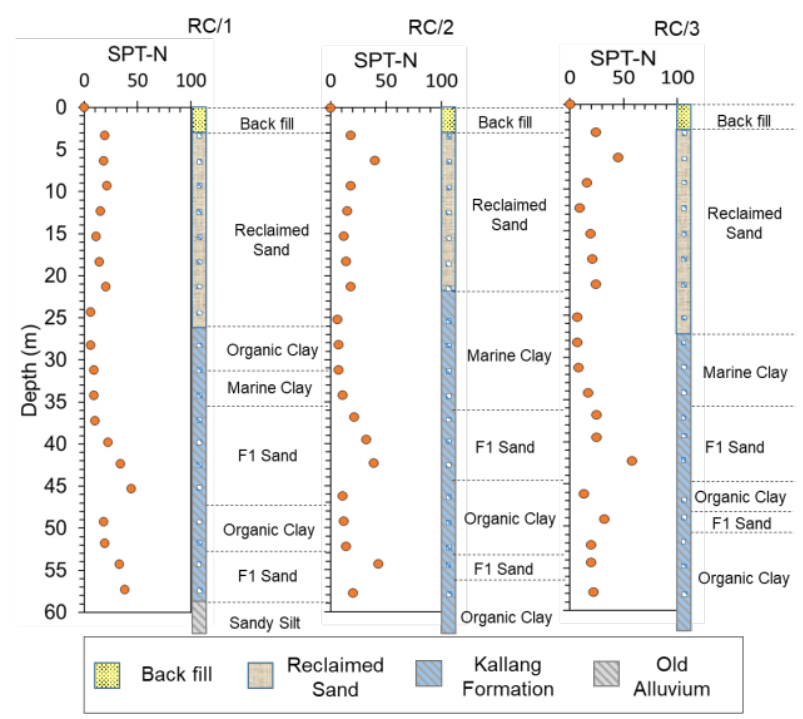

Fig. 2. Soil profile with the SPT- $N$ value.

\section{Equipment and Field Set-up}

\subsection{Borehole preparation}

After the borehole drilling works, a 40m long bottomcapped PVC pipe (with internal diameter $75 \mathrm{~mm}$ ) was inserted into each borehole. These would serve as casing for the cross-hole test source and receivers. The PVC pipes were then grouted to the surrounding soil mass according to the ASTM Standards [26]. It was important for the grout mixture to be formulated closely to the unit weight of the surrounding soil after solidification so as to ensure a good coupling between the soil and the downhole equipment. The verticality of the boreholes was then checked by lowering a Geotomographie Gmbh Borehole Deviation Probe into the borehole and acquiring measurements at every $1 \mathrm{~m}$ depth. The probe consists of a 3-axis magnetometer which allows tilt and direction angles to be recorded on a computer. Since the results of the deviation survey revealed that the inclination of three boreholes were negligible, it was assumed that the boreholes are vertical during the analysis of the seismic signals.

\subsection{Cross-hole testing equipment}

Cross-hole testing was conducted by lowering the seismic source in borehole $\mathrm{RC} / 1$ and the string of geophones in borehole RC/2. The seismic source used (see Figure 3a) was a Geotomographie BIS-SH-DS electro-mechanical probe capable of producing both $\mathrm{P}$-waves and horizontally polarised S-waves. It is powered by a Geotomographie impulse generator IPG800 which supplies an energy of $1000 \mathrm{~J}$ at a voltage of $800 \mathrm{~V}$ to it. During the test, the source probe was lowered into the borehole at a depth interval of $1 \mathrm{~m}$ and locked into position by inflating the packer so that it is tightly clamped to the borehole wall.

The receiver system is a Geotomographie Multistation Borehole Acquisition System (MBAS) which consists of a string of eight $30 \mathrm{~Hz}$-geophone stations (shown in Figure 3b), with a station interval of $1 \mathrm{~m}$. Each individual station contains three geophones arranged in a triaxial orthogonal manner and a digitizer for the analogto-digital conversion (24 bit). Hence, the whole set-up does not require a seismograph and is connected directly to a notebook via a USB interface. For each shot, the seismic signals were recorded for a duration of $1 \mathrm{~s}$ through the software SoilSpy Rosina at a sampling frequency of $4096 \mathrm{~Hz}$.

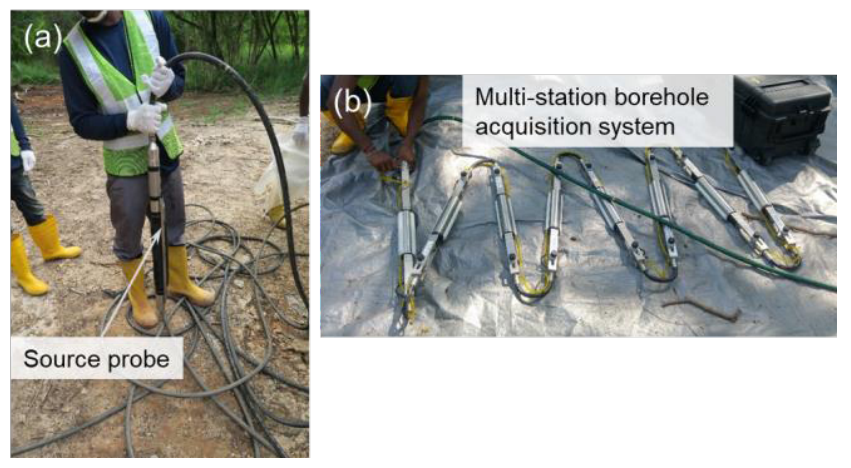

Fig. 3. Seismic cross-hole test equipment used in this study: (a) seismic source probe (b) Multi-station Borehole Acquisition System (MBAS). 


\section{Results and Discussion}

A sample of the received signals is shown in Figure 4 for the seismic source located at $10 \mathrm{~m}$ depth and the first geophone at a depth $6 \mathrm{~m}$. In this study, first arrival traveltime tomography (e.g. [29-30]) was used to interpret the seismic signals. The first arrival times for the P-wave and S-wave were manually picked in the SoilSpy Rosina software and compiled for inversion analysis. The commercial inversion software GeotomCG was used for that purpose. GeotomCG uses the simultaneous iterative reconstruction technique (SIRT) to perform inversions. McGauhey \& Young [31] compared SIRT to other inversion techniques such as the algebraic reconstruction technique (ART), least squares and singular value decomposition (SVD). They reported that SIRT is superior to ART in consideration of noise-contaminated data and that the usage of SVD is recommended if computation power and time are available.

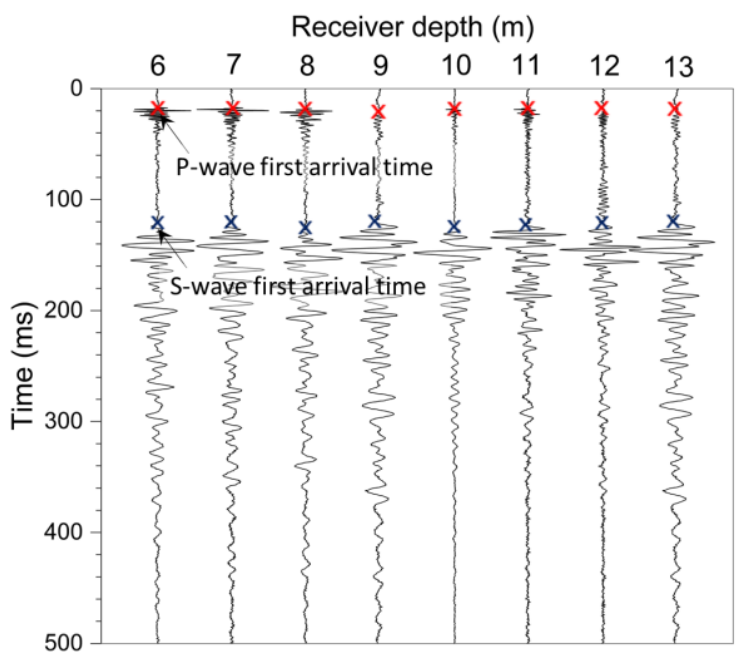

Fig. 4. Received signals for the horizontal component geophones. The source probe is located at a depth of $10 \mathrm{~m}$ and the first geophone at $6 \mathrm{~m}$. First arrival times are marked with a ' $x$ '.

The model grid for inversion analysis was divided into 28 horizontal cells $\times 42$ vertical square cells. Since the study area is not expected to contain high velocity contrasts which could cause ray-bending (e.g. [32-33]), a straight-ray inversion approach was adopted for the model. Based on the signal acquisition geometry during the field test, the resulting ray density plot (assuming straight rays) is depicted in Figure 5. The ray density plot shows the number of rays that affect the calculated velocity at a particular cell. In other words, the ray density at a point is the sum of the rays in cells with a corner at that point. The plot gives an indication of the resolving power of the seismic data and is a common criterion to assess one's confidence in the final travel time inversion solution [34]. Despite the non-uniform ray coverage of the target area, it is presumed that the inversion analysis would nonetheless yield reasonable results because of the uniform geology of the site.

The initial velocity model to initiate the iteration was a homogeneous soil profile with a velocity of $750 \mathrm{~m} / \mathrm{s}$ and $150 \mathrm{~m} / \mathrm{s}$ for the P-wave and S-wave travel time inversion respectively. The choice of the initial velocity is not critical and is chosen by default to be between the lowest and average straight line velocity in the dataset. The root mean square (RMS) residual, which is the difference between the measured travel time and calculated travel time, is computed after each iteration. This value was observed to stabilise after the $7^{\text {th }}$ iteration after which little improvement is brought to the velocity models. Consequently, the iterative process was stopped. The final $\mathrm{P}$-wave and $\mathrm{S}$-wave velocity models are shown in Figure 6 and 7 respectively.

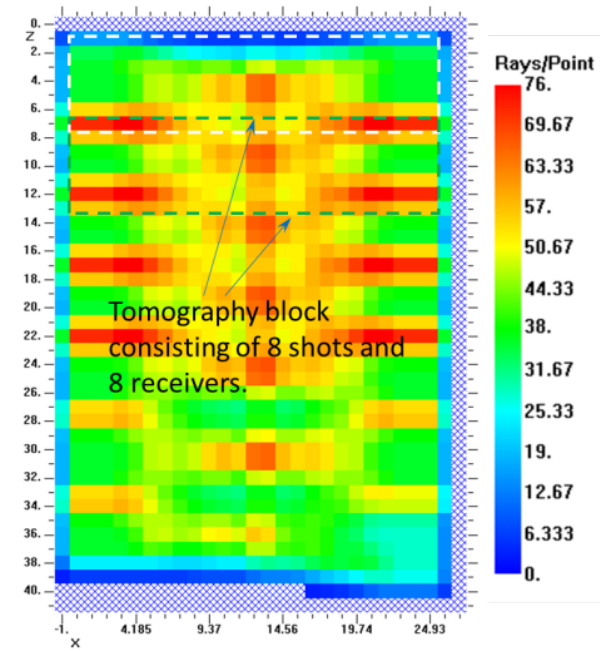

Fig. 5. Ray density plot, assuming straight ray tracing. The acquisition geometry consisted of overlapping tomography blocks of 8 shots and 8 receivers.

From both velocity models in Figure 6 and 7, it is observed that the distinction between the different soil layers is not very clear as compared to the soil stratification shown in Figure 2. The P-wave velocity model indicates that the stiffness of the soil gradually increases to a depth about $9 \mathrm{~m}$ beyond which the P-wave velocity seems to be constant at $\sim 1450 \mathrm{~m} / \mathrm{s}$. It has been well-reported in the literature that in multi-phase media like saturated soils, the P-wave velocity of the media is significantly influenced by the presence of pore water, depending on the degree of saturation (e.g. [35]). Figure 6 seems to indicate that the soil below $10 \mathrm{~m}$ is fully saturated since the measured $\mathrm{P}$-wave velocity is approximately equal to that of water. However, based solely on the Pwave tomogram, it appears that the water table is located at a depth of about $9 \mathrm{~m}$, which is slightly different from the borehole data. The latter indicated that the ground water table fluctuated between $3.5 \mathrm{~m}$ to $5.6 \mathrm{~m}$ below the ground level. Several studies (e.g. [36-37]) have used the $V_{p} / V_{s}$ ratio and/or Poisson's ratio $v$ to locate water bodies, in particular confined aquifers. For fully saturated soils, the Poisson's ratio value is close to 0.5 since water is incompressible. Adopting a similar approach in this study, the Poisson's ratio distribution of the soil layers was calculated by Eq. 1 and is shown in Figure 8. 


$$
v=\frac{\left(V_{P} / V_{s}\right)^{2}-2}{2\left[\left(V_{P} / V_{s}\right)^{2}-1\right]}
$$

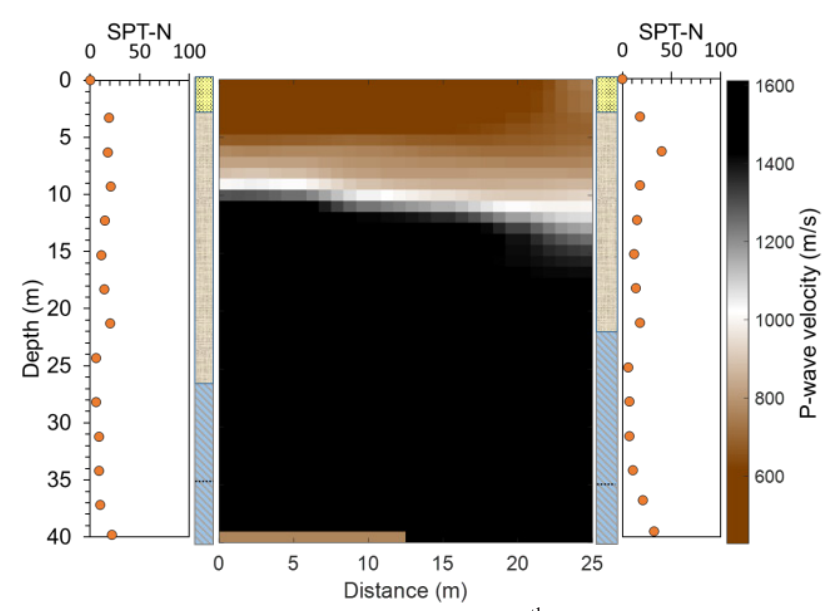

Fig. 6. P-wave velocity model after the $7^{\text {th }}$ iteration. The variation of the SPT- $N$ value with depth is also shown for the same boreholes.

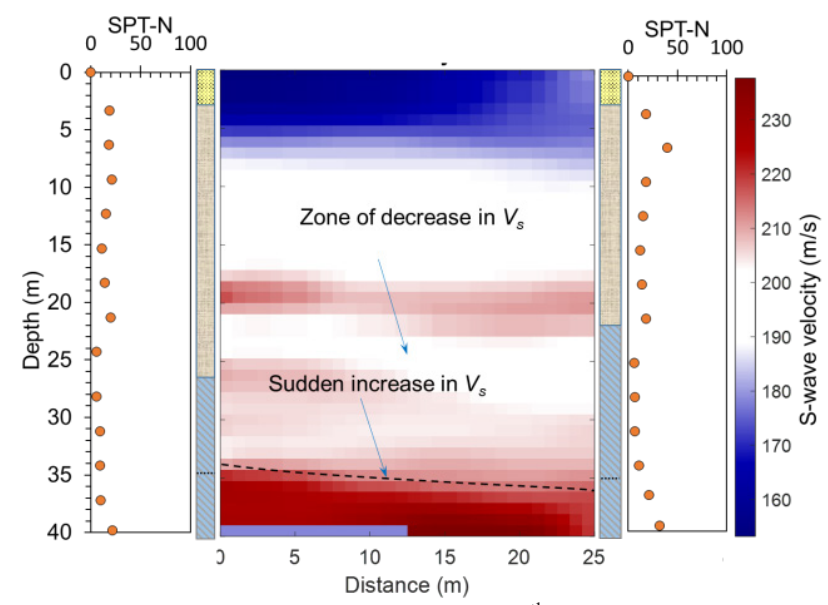

Fig. 7. S-wave velocity model after the $7^{\text {th }}$ iteration. The variation of the SPT- $N$ value with depth is also shown for the same boreholes.

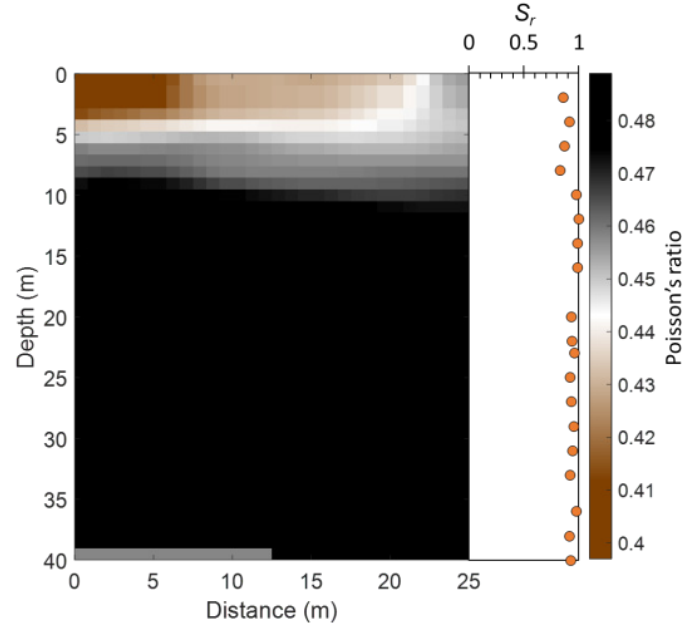

Fig. 8. Distribution of Poisson's ratio computed from the Pwave and S-wave velocity models. The degree of saturation of the soil for a nearby borehole is also shown alongside.
As mentioned above, the borelog information from the three boreholes in the study area showed that the ground water table fluctuated between $3.5 \mathrm{~m}$ to $5.6 \mathrm{~m}$ below the ground level, but no information was available about the water content of the soil. We had to rely on the information from a nearby borehole - located on the same reclaimed land - to plot the variation of degree of saturation $S_{r}$ with depth. Figure 8 seems to suggest that the Poisson's ratio shows a good agreement with the trend exhibited by the degree of saturation. The partial saturation of the reclaimed sand within the first few metres can be attributed to the ground water level fluctuation and is consistent with the borelog information.

Regarding the shear wave velocity $\left(V_{s}\right)$ tomogram, the model shows an increase in $V_{s}$ to a depth of about $21 \mathrm{~m}$, after which $V_{s}$ decreases. This corresponds to the transition zone between the reclaimed sand and marine clay layer. It can also be observed that the range of $V_{s}$ values is closely banded over the depth of $15 \mathrm{~m}-30 \mathrm{~m}$ although the two soil types are very different from each other. This can be explained by the fact that a sand layer typically returns a higher shear wave velocity than a clay layer under the same effective stress conditions; since the shear wave velocity depends on the stiffness of soil grain skeleton, relatively stiff sandy particles with the enhanced grain-to-grain contact can produce a higher velocity. In the scenario where a sandy layer exists above a clay deposit, the higher inherent 'speed' of the sandy layer could be offset by the higher overburden in-situ stresses which are acting on the clay layer. At a depth of $35 \mathrm{~m}$, the shear wave velocity tomogram shows a sudden increase in the $V_{s}$, which corresponds to the fluvial sand layer. Hence, the interface between the different soil layers could be identified from the velocity model. It is also worthy to note that the trend in the SPT- $N$ value is quite consistent with the $V_{s}$ trend. For instance, site-specific features like the increase in the SPT- $N$ value in the $15 \mathrm{~m}-$ $20 \mathrm{~m}$ range, the sudden drop in the SPT- $N$ value due to the soft clay layer and the increase due to the fluvial sand layer are well-reproduced by the velocity model.

\section{Summary and Conclusion}

Seismic cross-hole testing, or more precisely first arrival travel-time wave tomography was conducted at a reclaimed land in the Eastern part of Singapore. Both Pwave and $\mathrm{S}$-wave arrival time information could be effectively obtained from a single shot generated by the seismic source, and using multiple receivers. The travel time data was then inverted into a velocity model using SIRT. It was observed that both the P-wave and S-wave velocity models carried different information about the soil profile at the site. While the $\mathrm{P}$-wave velocity model is strongly influenced by the ground water table, the S-wave velocity could identify the soil layer interface between the reclaimed sand, marine clay and the fluvial sand. At this particular site, the $V_{s}$ profile was affected by the sandover-clay layer configuration which masks the impedance contrast between the two types of soil. Furthermore, the $\mathrm{S}$-wave velocity model seems to agree well with the trend in the SPT- $N$ value and the Poisson's ratio plot was found 
to provide a good indication of the degree of saturation of the soil.

We are grateful to our collaborators from the Geotechnical and Tunnels Division of the Infrastructure Design and Engineering Group at the Land Transport Authority of Singapore and from Ryobi Geotechnique Singapore for their logistical support in planning for this field test as well as during the course of testing. This project is supported by the Ministry of National Development (MND) under its Land and Liveability National Innovation Challenge (L2 NIC Awards No. L2NICCFP2-2015-2).

\section{References}

1. P. Hurley, University of Toronto, Master thesis (1983)

2. M. Fehler and C. Pearson, Geophysics 49, 1, 37 (1984)

3. J. Wong, N. Bregman, G. West, and P. Hurley, The Leading Edge 6, 1, 36 (1987)

4. N. Bregman, R. Bailey, and C. Chapman, Geophysics 54, 2, 200 (1989)

5. N. Bregman, P. Hurley, and G. West, Geophysics 54, 9, 1082 (1989)

6. P. L. Inderwiesen and T.-w. Lo, in SEG Technical Program Expanded Abstracts 1990 (Society of Exploration Geophysicists, 1990), pp. 22

7. D. S. Lee, V. M. Stevenson, P. F. Johnston, and C. Mullen, Geophysics 60, 3, 660 (1995)

8. D. W. Vasco, Geophysics 69, 2, 511 (2004)

9. M. Zhdanov, G. Vignoli, and T. Ueda, Journal of Geophysics and Engineering 3, 2, 122 (2006)

10. Y. Jung, A. Ibrahim, and D. Borns, The Leading Edge 10, 4, 37 (1991)

11. M. J. Friedel, D. R. Tweeton, M. Jackson, J. Jessop, and S. Billington, in SEG Technical Program Expanded Abstracts 1992 (Society of Exploration Geophysicists, 1992), pp. 58.

12. S. Cao and S. Greenhalgh, Geophysical Prospecting 45, 3, 449 (1997)

13. J. Wong, Geophysics 65, 6, 1900 (2000)

14. D. Kieffer, M. Bluemel, and K. Hanna, presented at the The 42nd US Rock Mechanics Symposium (USRMS), 2008 (unpublished)

15. K. Xu and S. Greenhalgh, Journal of Applied Geophysics 70, 1, 38 (2010)

16. A. Nalonnil and B. Marion, SPE Reservoir Evaluation \& Engineering 15, 1, 25 (2012)

17. K. Katterbauer and I. Hoteit, presented at the SPE Heavy Oil Conference-Canada, 2014 (unpublished).

18. H. Saito, D. Nobuoka, H. Azuma, Z. Xue, and D. Tanase, Exploration Geophysics 37, 1, 30 (2006)

19. F. Zhang, C. Juhlin, C. Cosma, A. Tryggvason, and R. G. Pratt, Geophysical Journal International 189, 1, 629 (2012)

20. A. Becht, C. Bürger, B. Kostic, E. Appel, and P. Dietrich, Journal of hydrology 336, 1-2, 171 (2007)

21. R. Hoover, in Sinkholes and the Engineering and Environmental Impacts of Karst (2003), pp. 529

22. D. Hiltunen and P. W. Dunn, in Underground Constructin and Ground Movement (2006), pp. 42
23. C. Duan, C. Yan, B. Xu, and Y. Zhou, Engineering Geology 28, 180 (2017)

24. T. Angioni, R. D. Rechtien, S. J. Cardimona, and R. Luna, Tectonophysics 368, 1, 119 (2003)

25. S. Mackens, Y. Hocine, and U. Werban, Journal of Environmental and Engineering Geophysics 22, 3, 291 (2017)

26. A. Standard, ASTM Int (2004)

27. M. W. Bo, J. Chu, and V. Choa, Elsevier GeoEngineering Book Series 3, 247 (2005)

28. M. W. Bo, M.-F. Chang, A. Arulrajah, and V. Choa, Geotechnical and Geological Engineering 30, 1, 45 (2012)

29. R. P. Bording, A. Gersztenkorn, L. R. Lines, J. A. Scales, and S. Treitel, Geophysical Journal International 90, 2, 285 (1987)

30. P. R. Williamson and M. Worthington, Geophysics 58, 5, 727 (1993)

31. K. McGaughey and R. Young, in SEG Technical Program Expanded Abstracts 1990 (Society of Exploration Geophysicists, 1990), pp. 74

32. J. Um and C. Thurber, Bulletin of the Seismological Society of America 77, 3, 972 (1987)

33. T. Moser, Geophysics 56, 1, 59 (1991)

34. E. Leong and Z. Cheng, International Journal of Geomechanics 16, 6, D4016013 (2016)

35. $35 .^{1} \mathrm{Y}$. Wang and Y. Rao, Geophysical Journal International 166, 3, 1224 (2006)

36. J. P. Castagna, M. L. Batzle, and R. L. Eastwood, Geophysics 50, 4, 571 (1985)

37. S. Pasquet, L. Bodet, A. Dhemaied, A. Mouhri, Q. Vitale, F. Rejiba, N. Flipo, and R. Guérin, Journal of Applied Geophysics 113, 38 (2015) 